\title{
DIAGNÓSTICO DO MEIO FÍSICO DA BACIA HIDROGRÁFICA DO RIO CONGONHAS, MG
}

\author{
Alethéa Ernandes Martins Sallun ${ }^{1}$, William Sallun Filho ${ }^{1}$, Ivo Karmann ${ }^{2}$ \\ Resumo \\ Para o diagnóstico ambiental do meio físico na Bacia Hidrográfica do Rio Congonhas (MG) realizaram-se \\ estudos geológico, geomorfológico e hidrogeológico para a caracterização sob o ponto de vista ambiental. \\ A região enfrenta muitos problemas relacionados a falta d'água, onde é elevado o índice de insucesso na \\ perfuração de poços tubulares profundos, devido ao clima desfavorável, solos ausentes e/ou delgados e a \\ natureza fissural da maior parte dos aqüíferos. Com a implantação da Barragem Congonhas, haverá aumento \\ da disponibilidade hídrica na região e poderão surgir problemas ambientais devido a atividade antrópica. \\ Não foram identificados pontos de degradação ambiental atuantes na bacia estudada, e os dados obtidos \\ forneceram subsídios para o zoneamento ambiental e desenvolvimento sustentável. Propõe-se ações de \\ educação ambiental voltadas a conscientização da população local, que pode ser atuante na identificação e \\ prevenção de fatores degradantes que proporcionam impactos ambientais.
}

Palavras-chave: geologia, geomorfologia, hidrogeologia, Rio Congonhas

\begin{abstract}
For the diagnosis of the physical environment of the Congonhas River Hydrographic Basin (Minas Gerais State), geological, geomorphological and hydrogeological studies were realized in order to environmental characterization. The region faces many problems of lack of water, with high rate of failure in the drilling of wells, due to unfavorable weather, absence and/or thin soil and fissural nature of most aquifers. With the implanting of the Congonhas dam, there will be increased water availability in the region and environmental problems may arise due to human activity. Were not identified points of environmental degradation acting in the studied basin and the information obtained provided data for the environmental zoning and sustainable development. It proposes actions for environmental education focused on awareness of local people, who can be active in the identification and prevention of factors of degradation that provide environmental impacts.v
\end{abstract}

Keywords: geology, geomorphology, hidrogeology, Rio Congonhas

\section{INTRODUÇÃO}

A Bacia Hidrográfica do Rio Congonhas localiza-se nos municípios de Juramento, Itacambira, Grão Mogol e Francisco Sá, no nordeste do estado de Minas Gerais (Figura 1). O Rio Congonhas está inserido no trecho alto do Rio Jequitinhonha, sendo tributário do Rio Itacambiruçu, um dos mais significativos tributários da margem esquerda do Rio Jequitinhonha.

Com a implantação da Barragem Congonhas na Bacia Hidrográfica do Rio Congonhas, considerada o maior investimento de recursos hídricos nesta região que enfrenta muitos problemas relacionados a falta d'água, poderão surgir problemas ambientais devido a atividade antrópica. Dessa forma, foram realizados estudos de diagnóstico ambiental do meio físico da área potencialmente atingida pela Barragem Congonhas, delimitada pela Bacia de Hidrográfica do Rio Congonhas com cerca de $577,563 \mathrm{~km}^{2}$, sendo que o enchimento do reservatório irá afetar uma superfície de $107,293 \mathrm{~km}^{2}$.

\section{CONTEXTO GEOLÓGICO E GEOMORFOLÓGICO}

A Serra do Espinhaço, denominada "Cordilheira do Espinhaço" por Eschwege (1822), é uma cadeia montanhosa alinhada na direção NS e que se estende por cerca de $1.200 \mathrm{~km}$ desde a Região Central de Minas Gerais até o norte da Bahia. A serra destacase na fisiografia da porção central de Minas Gerais, constituindo-se no divisor de águas entre as bacias do Rio São Francisco, a oeste, e dos rios Doce, Jequitinhonha e Pardo, a leste.

Segundo Saadi (1995) a organização geomorfológica da Serra do Espinhaço é controlada por fatores geológicos, com a existência de dois platôs bem diferenciados, denominados Planalto Meridional e Planalto Setentrional. Estes planaltos refletem o contraste litoestrutural entre as porções sul e norte da serra, e sua morfologia reflete a expressão morfológica da associação entre resistência litológica frente a processos erosivos e seus arranjos tectônicos 


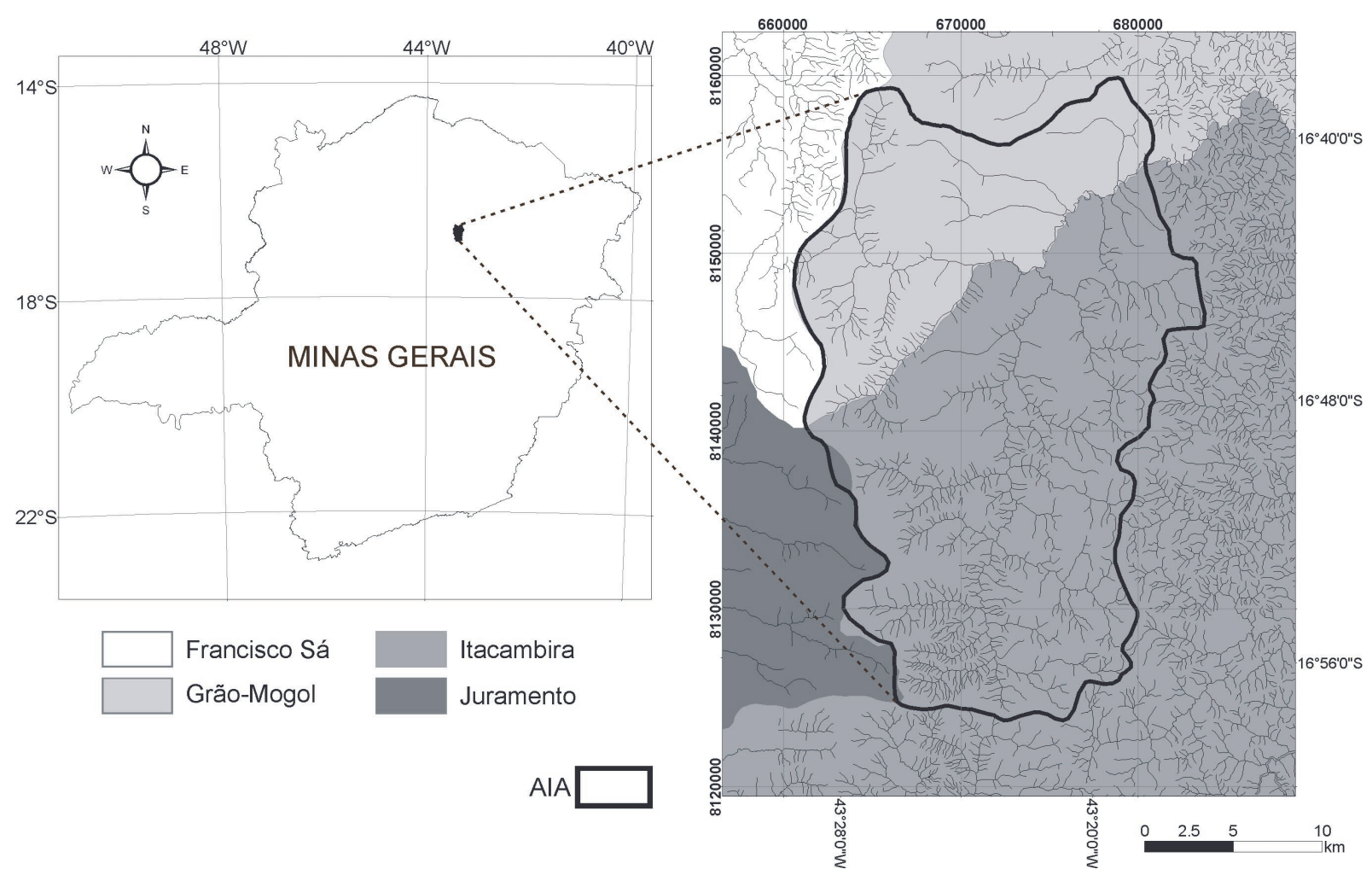

Figura 1: Localização área em estudo no Estado de Minas Gerais.

(Saadi 1995). A morfologia das porções superiores dos planaltos é caracterizada por reliquiares de duas superfícies terciárias de aplainamento, resultantes de processos erosivos sob condições tropicais úmidas (Saadi 1995).

Entre duas linhas de serras do sistema Espinhaço está encaixada a Bacia Hidrográfica do Rio Congonhas, no Vale do Jequitinhonha (Folha Botumirim escala 1:100.000, SE-23-X-B-IV IBGE), em uma faixa $20 \mathrm{~km}$ de largura e altitudes de 870 e $1330 \mathrm{~m}$. A bacia é limitada a oeste pela porção ocidental da Serra do Catuni, e a oeste pelo Sistema Espinhaço, com vários segmentos proeminentes, como a serra do Espaduado e da Porteira. Ao sul, a região da nascente do Rio Congonhas faz divisa com a Bacia Hidrográfica do Rio Macaúbas através da Serra do Catuni, de direção leste-oeste, onde ocorre a altitude máxima de $1242 \mathrm{~m}$.

A Bacia Hidrográfica do Rio Congonhas está situada no domínio da faixa móvel que define o limite à oeste e a norte com o Cráton do São Francisco e a leste com a Província Costeira, na extremidade nordeste da Província da Mantiqueira. A região pode ser dividida em dois grandes domínios estruturais: Domínio I, constituído pelas rochas que compõem o embasamento pré-Espinhaço (Complexo Córrego do Cedro e Suíte Rio Itacambiruçu) e Domínio II, englobando as coberturas metassedimentares (Supergrupo Espinhaço e grupos Macaúbas e Bambuí) (Grossi Sad et al. 2002)

A distribuição das unidades geológicas maiores é condicionada pela presença de uma faixa alongada no sentido meridional, com largura média em torno de 30 $\mathrm{km}$, onde está exposto o embasamento pré-Espinhaço. Esta faixa é interpretada como o núcleo de uma grande estrutura antiformal com caimento para sul e flanqueada pelas unidades mais novas: Supergrupo Espinhaço e Grupo Macaúbas. O embasamento préEspinhaço apresenta uma extensa exposição de rochas gnáissicas, geralmente bandadas, com freqüentes corpos concordantes de anfibolito e podendo exibir feições de migmatização. Completam o conjunto do embasamento diversos corpos granitóides, foliados ou não, intrusões máfico-ultramáficas e uma seqüência xistosa, de provável origem vulcano-sedimentar (Grossi Sad et al. 2002).

O contato das unidades metassedimentares com o embasamento granito-gnáissico é sempre marcado por zonas de cisalhamento subhorizontais, caracterizando a natureza alóctone das primeiras sobre o segundo. Destacam-se ainda os diques e soleiras de metadiabásios intrusivos nas rochas do embasamento e do Supergrupo Espinhaço e também os diques clásticos, quartzíticos e conglomeráticos, de direção NE ou NW, encravados em fraturas do embasamento (Grossi Sad et al. 2002).

\section{MATERIAIS E MÉTODOS}

O estudo envolveu o mapeamento morfológico e litológico, com a aplicação de técnicas morfométricas, mapeamento e o prognóstico da susceptibilidade à degradação devido a processos ambientais impactantes.

Foram utilizados produtos de sensoriamento remoto e geradas cartas temáticas utilizando Sistema de Informação Geográfica (SIG) para análise morfométrica do relevo, utilizando os softwares ARCGIS e os dados estão referenciados em UTM no datum SAD69. 
A compartimentação geomorfológica e a extração de lineamentos foram realizadas através de fotos aéreas, imagens de satélite e de radar. Foram utilizados recortes georreferenciados de imagem multiespectral do sensor ETM+ do satélite LANDSAT 7 (órbita 218 e ponto 72 - junho de 2000) com resolução 30 e $15 \mathrm{~m}$. Modelo digital de terreno (MDT) foi gerado a partir de dados SRTM (Shuttle Radar Topography Mission - NASA) com resolução $90 \mathrm{~m}$. Para confecção dos estereogramas em rosáceas foi utilizado o programa QUICKPLOT (Van Everdingen \& Van Gool 1990).

As composições da imagem do satélite LANDSAT-7 foram processadas, utilizando as bandas ETM +1 , 2, 3, 4, 5, 6, 7 e 8 do sensor ETM+, com fusão para aumentar a resolução espacial $(15 \times 15 \mathrm{~m})$, sem perder as propriedades radiométricas. Foi feita também análise por componentes principais (PC1) cálculo de índices de vegetação a partir das equações: - Banda 4 / Banda 7 e - Banda 2 / (Banda 1 x Banda 3).

Os dados de SRTM (2006) foram obtidos no site http://strm.usgs.gov, e contém dados de topografia obtidas por radar. A partir da topografia foram elaborados o Modelo Digital de Terreno (MDT), mapa hipsométrico e extraídos os índices morfométricos, Mapa de declividade de encostas e Mapa de orientação de encostas.

Foram delimitadas as sub-bacias e estudo do perfil longitudinal do Rio Congonhas para a caracterização atual do nível de base local, determinando o fluxo do escoamento superficial. Foi realizada uma simulação da vulnerabilidade do aqüífero a contaminação pelo método GOD: Grau de confinamento hidráulico, Ocorrência de substrato suprajacente (características litológicas e grau de consolidação da zona não saturada e camadas confinantes) e Distância do nível da água subterrânea (Foster et al. 2002).

\section{GEOLOGIA}

$\mathrm{Na}$ área de estudos são reconhecidos três conjuntos litológicos (Figura 2): o Supergrupo Espinhaço, o Grupo Macaúbas e os Depósitos Cenozóicos. Predominam em expressão de área os Depósitos Cenozóicos, seguidos do Grupo Macaúbas e do Supergrupo Espinhaço.

O Supergrupo Espinhaço ocupa $116 \mathrm{~km}^{2}$ (20\% da área de estudos) e caracteriza-se essencialmente por um pacote homogêneo de quartzitos com estruturas sedimentares primárias preservadas, com marcas onduladas e estratificação cruzada, e acamamento de direção NE-SW, com mergulhos ora para SE ora para NW (Figura 3).

O Grupo Macaúbas ocupa $174 \mathrm{~km}^{2}$ (30\% da área de estudos), composto por metadiamictitos com intercalações de quartzitos impuros e de metassiltitos. $\mathrm{O}$ Grupo Macaúbas em parte que não foi dividido (Grupo Macaúbas Indiviso), devido a difícil caracterização das faixas estreitas e isoladas muito deformadas, reconhecendo-se somente a Formação Serra do Catuni. Uma faixa de rochas denominada Grupo Macaúbas
Indiviso é atingida nas porções das altas cabeceiras dos córregos Miséria e Fartura. São constituídos de filitos e quartzitos ferruginosos, localmente com intercalações de metadiamictito.

A Formação Serra do Catuni aflora nas cabeceiras do vales fluviais, constituída por metadiamictitos de matriz filítica (com quartzo, carbonato e feldspato), contendo fragmentos angulosos e de tamanhos variados, de quartzo, quartzito, granitóide, gnaisses e calcário; subordinadamente ocorrem camadas e lentes descontínuas de quartzitos impuros, mal selecionados, posicionados na base ou em intercalações. O contato com entre a Formação Serra do Catuni e o Grupo Macaúbas Indiviso situa-se próximo ao curso do Rio Congonhas. O contato entre as unidades rochosas do Supergrupo Espinhaço e Grupo Macaúbas é discordante erosivo.

Os Depósitos Cenozóicos compreendem sedimentos detrito-lateríticos e aluviões que ocupam $286 \mathrm{~km}^{2}$ de área ( $50 \%$ da área de estudos).

Os sedimentos detrito-lateríticos (47\% da área de estudos), são constituídos de sedimentos areno-argilosos com areia fina a média, argila siltosa amarelada e marrom avermelhada, localmente com cascalho, depositados sobre uma superfície de aplainamento. Podem alcançar dezenas de metros de espessura e se distribuem em altitudes de 900 a 1300 m. Estes depósitos de origem coluvial e eluvial, possuem níveis de cascalhos, seixos e fragmentos de quartzo, ora cimentados por óxidos e hidróxidos de ferro formando ferricretes, inconsistentes ou parcialmente laterizados, e podem alcançar dezenas de metros de espessura.

Aluviões ( $3 \%$ da área de estudos) ocorrem ao longo do Rio Congonhas e de outras drenagens associadas. São constituídos essencialmente de areias, desde finas até grossas, e subordinadamente silte e argila (Figura 3). Em alguns pontos próximos do leito, os aluviões formam pequenas manchas alagadiças e lagoas além de bancos de areia que variam de areia fina a areia grossa com seixos. Localmente ocorrem na base desses sedimentos, camadas de cascalho e areia, com seixos e blocos de quartzo, quartzito, limonita, metaconglomerado e metasssiltito e areia fina a grossa.

\section{GEOLOGIA ESTRUTURAL}

Foi identificada por Grossi Sad et al. (2002) uma falha ocorre uma grande linha de falha de deslocamento basal, que afetou as rochas da área de estudo através de zonas de cisalhamento, falhas e com provável basculamento do pacote metassedimentar.

$\mathrm{O}$ acamamento possui uma direção geral NE-SW com mergulho em geral para WNW e foliação de direção geral NE-SW com mergulho para NW, e N-S com mergulho para W.

$\mathrm{O}$ vale do Rio Congonhas e suas cachoeiras estão litoestruturalmente subordinados a faixas de cisalhamento (secundárias), acompanhando parcialmente uma grande faixa milonitizada. Ocorre um 


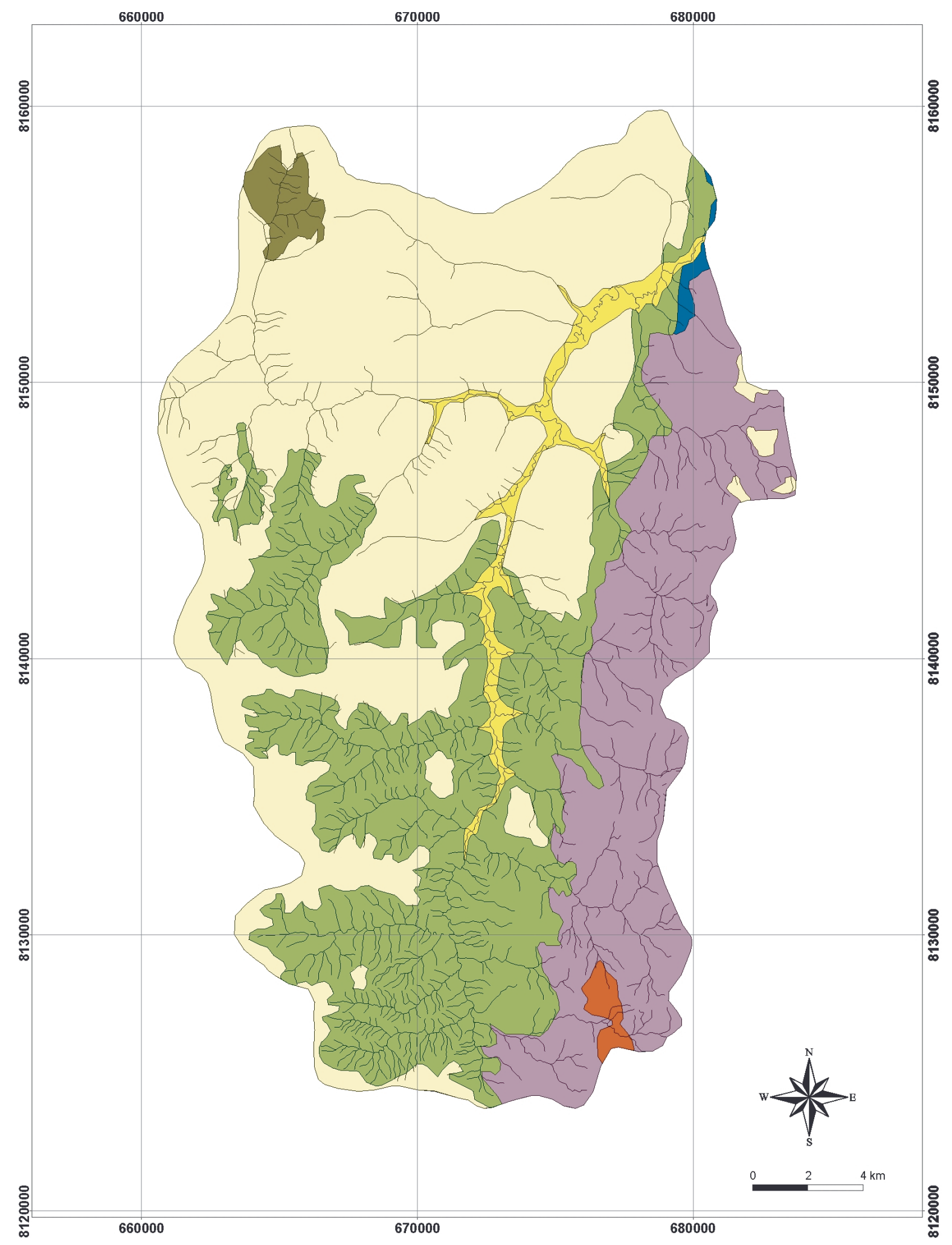

\section{Depósitos cenozóicos Grupo Macaúbas}

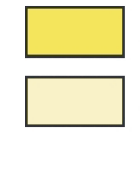
Aluviões

Coberturas detrito-lateríticas

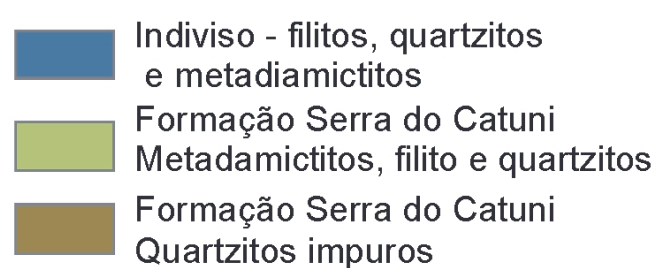

Supergrupo Espinhaço

Quartzitos e metaconglomerados Metadiabásio Quartzitos impuros

Figura 2: Mapa litológico da Bacia Hidrográfica do Rio Congonhas (modificado de Grossi Sad et al. 2002). 

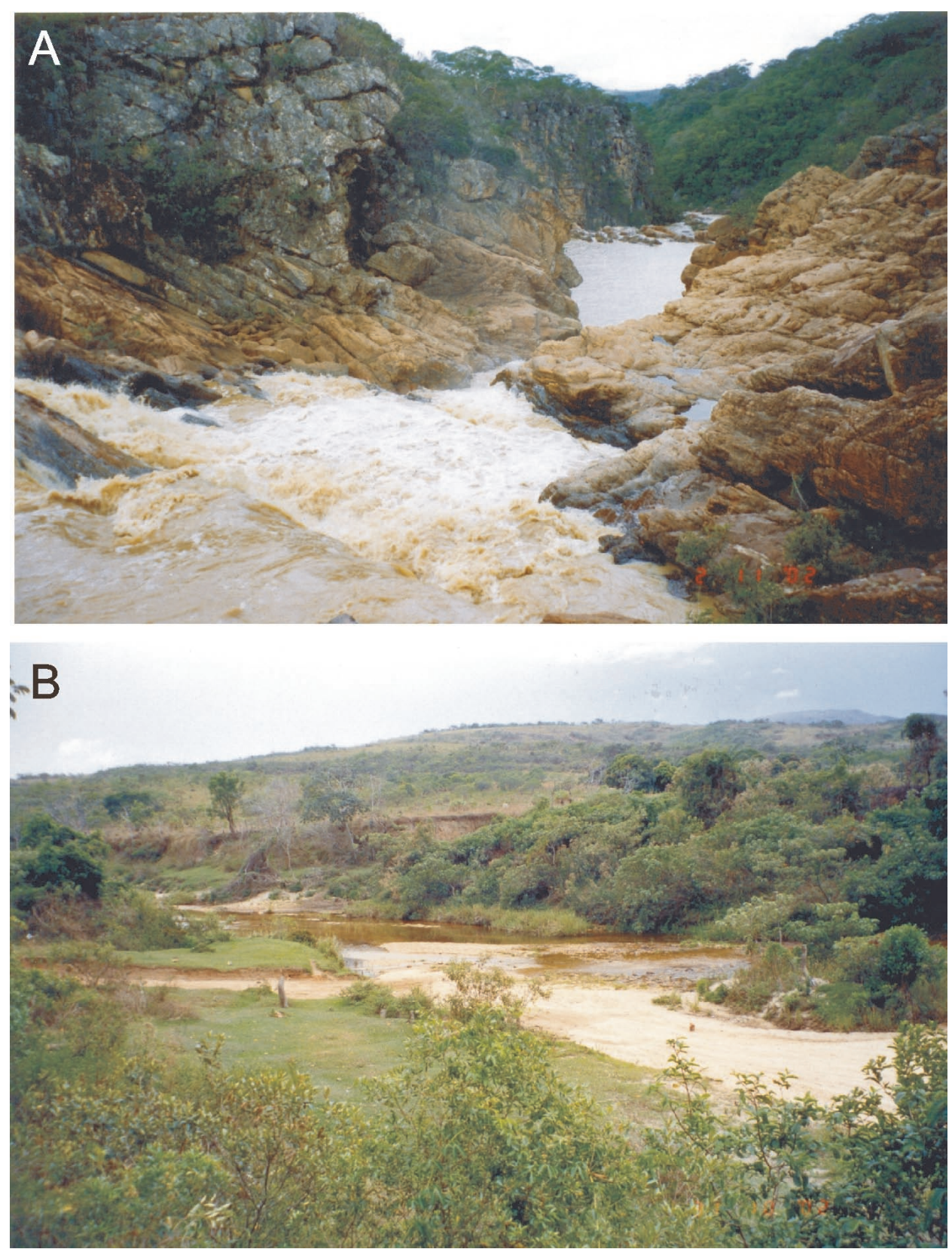

Figura 3: A) Cachoeira a jusante no Rio Congonhas, na futura área do barramento, com quartzitos do Supergrupo Espinhaço exibindo planos de estratificação, formando um vale encaixado; B) Vista do setor médio do curso do Rio Congonhas, em vale aberto com vertentes recuadas e amplas planícies aluviais com terraços fluviais e acúmulo de areias e cascalheiras de idade quaternária.

deslocamento basal de alto ângulo, aproximadamente no sentido leste-oeste, é o maior valor do ângulo de mergulho da camada de quartzito a montante da falha (corpo de milonito), enquanto a jusante esse valor são menores e mais suaves. Observou-se em campo que falhas na direção N73E com mergulho de 15 para NW, e de possível movimentação inversa. A análise por fotolineamento indica direções preferenciais neste local de N60E relativas às zonas de cisalhamento. A análise das fraturas indicaram diversas famílias mas duas direções se destacam: principal é NW, especialmente N320-350, e NE, variam entre N60-80. Um outro conjunto NE, de menor importância, é observado nas direções N0-40.
Foram extraídos 261 lineamentos na Bacia Hidrográfica do Rio Congonhas (Figura 4), com uma maior freqüência nas direções NE, especialmente N030, e NW especialmente N300-360. Em termos de comprimento, os lineamentos mais longos predominam nas direções NW, especialmente N300-320, e NE especialmente $\mathrm{N} 20-40$.

Os lineamentos de direção NE são associados a falhas regionais, estruturas de acamamento, foliação ou bandamento metamórfico, e de direção NW a estruturas rúpteis como falhas e fraturas. Em termos de comprimento, as direções NW ficam mais evidentes entre N290 e N320, indicando a possível existência de falhas regionais nestas direções. 


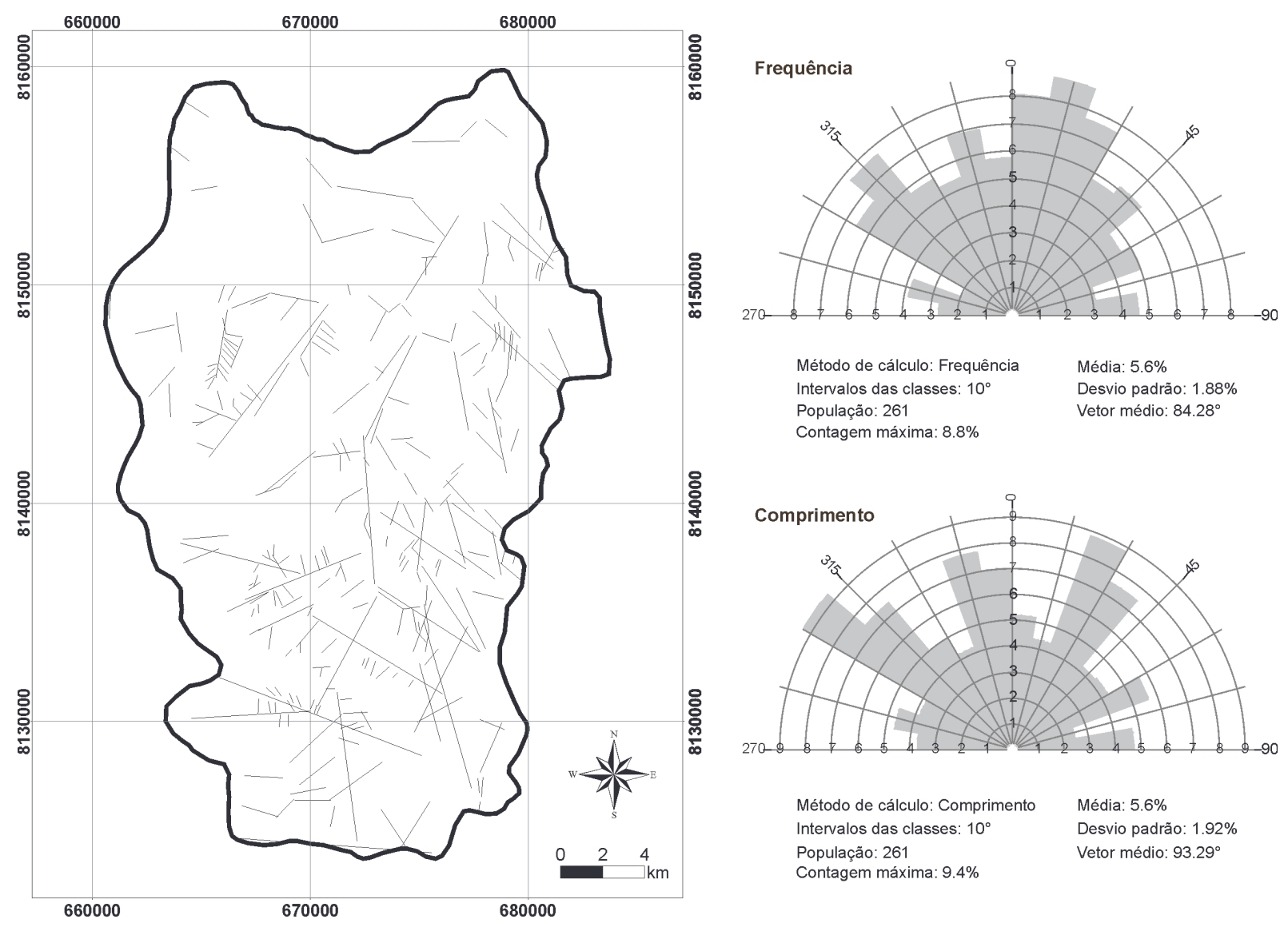

Figura 4: Lineamentos associados a falhas no Rio Congonhas, e respectivos diagramas em rosácea em termos de freqüencia e de comprimento.

\section{GEOMORFOLOGIA}

O gradiente hidráulico do Rio Congonhas é predominantemente baixo $(\sim 0,2 \%)$, adquirindo maiores gradientes a jusante $(0,3 \%$ a $2 \%)$ e nas cabeceiras de drenagem ( $14 \%$ a $2 \%$ ). Constatou-se que mudanças que ocorrem na morfologia no curso do Rio Congonhas estão associadas com as condições litoestruturais do substrato, resultando em um forte controle de compartimentos pela delimitação geológica (Figura 5).
Foram reconhecidas quatro unidades geomorfológicas maiores (Figura 6 e Tabela 1), assim como em outros estudos (IGA 1978, CETEC 1980 e IBGE 1997), a partir da análise de fotografias aéreas, dos mapas hipsométrico, declividades e orientação das vertentes e estudo de perfis topográficos (Figura 7).

\section{CHAPADAS DO ALTO JEQUITINHONHA}

Ocorrem praticamente a oeste do Rio Congonhas (margem esquerda) e algumas manchas são encontradas

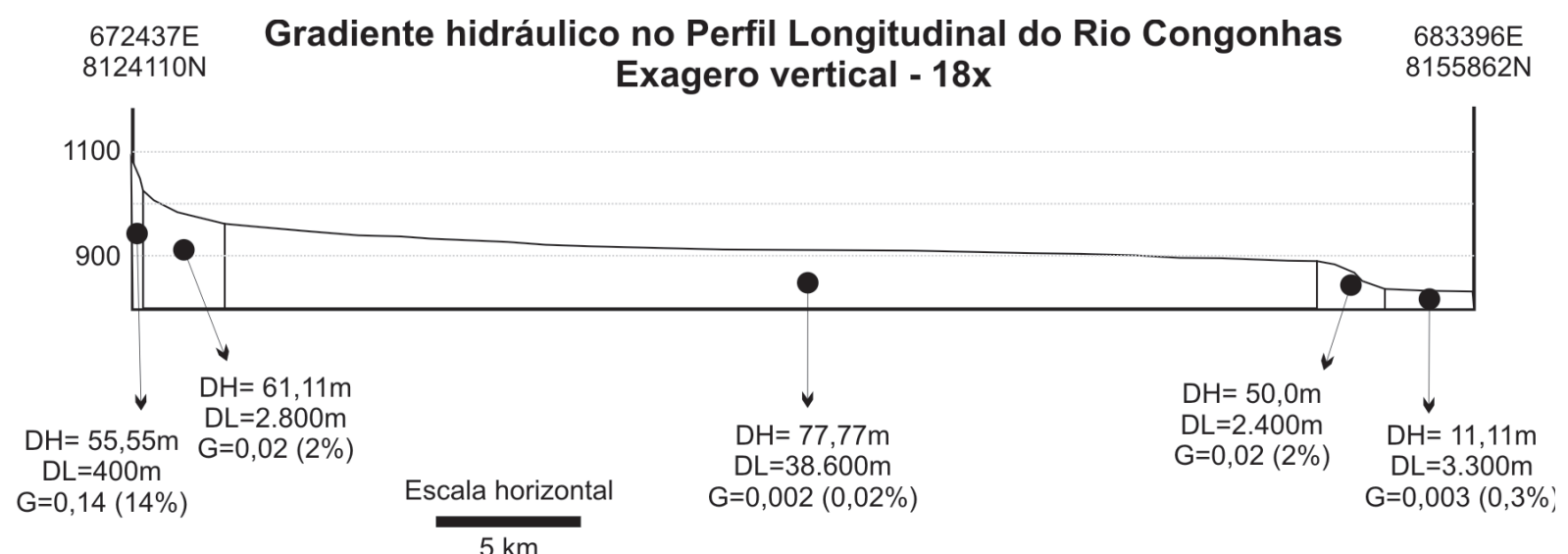

Figura 5: Perfil longitudinal do Rio Congonhas com gradiente hidráulico dos diversos setores (DH: altura, DL: comprimento, G: gradiente). 
Tabela 1: Unidades geomorfológicas da área estudada e duas principais características.

\begin{tabular}{|c|c|c|c|c|}
\hline $\begin{array}{l}\text { unidade geomor- } \\
\text { fológica }\end{array}$ & declividade & $\begin{array}{l}\text { escoamento } \\
\text { superficial }\end{array}$ & $\begin{array}{l}\text { altimetria } \\
(\mathrm{m})\end{array}$ & $\begin{array}{c}\text { área que ocupa } \\
\text { na bacia }(\%)\end{array}$ \\
\hline $\begin{array}{l}\text { Chapadas do Alto } \\
\text { Jequitinhonha }\end{array}$ & $\begin{array}{c}0 \text { a } 18^{\circ} \\
\text { maioria } 0 \text { a } 10^{\circ}\end{array}$ & $\begin{array}{l}\text { densidade de } \\
\text { drenagem } \\
\text { muito menor }\end{array}$ & 910 a 1300 & 40 \\
\hline $\begin{array}{l}\text { Patamares Dis- } \\
\text { secados do Espin- } \\
\text { haço }\end{array}$ & $\begin{array}{c}0 \text { a } 53^{\circ} \\
\text { maioria } 5 \text { a } 18^{\circ} \\
18 \text { a } 53^{\circ} \text { - vale (ín- } \\
\text { areme a penhasco) }\end{array}$ & $\begin{array}{l}\text { forte controle } \\
\text { estrutural }\end{array}$ & 1330 a 1910 & 19 \\
\hline $\begin{array}{l}\text { Planalto Disseca- } \\
\text { do do Alto Jequit- } \\
\text { inhonha }\end{array}$ & $\begin{array}{c}\text { greme a pennasco) } \\
0 \text { a } 53^{\circ} \\
0-18^{\circ} \text { - vale }\end{array}$ & $\begin{array}{l}\text { maior rugosi- } \\
\text { dade }\end{array}$ & 870 a 1200 & 38 \\
\hline Planície Aluvial & 0 a $5^{\circ}$ & $\begin{array}{l}\text { vale do rio } \\
\text { encaixado }\end{array}$ & 870 a 940 & 3 \\
\hline
\end{tabular}

a leste (margem direita). Apresentam topos nivelados por superfície de aplainamento da Superfície SulAmericana (King 1956) fragmentada pela intensa dissecação que elaborou os modelados adjacentes, formando amplas colinas que apresentam textura lisa.

Concreções ferruginosas que originam crostas lateríticas contribuem para a manutenção da topografia. Nesta unidade a drenagem assume padrão dendrítico com pouca expressão superficial e baixa densidade de drenagem.

As superfícies de cimeira das "Chapadas do Alto Jequitinhonha" são tabulares e recobertas por coberturas detrito-lateríticas, que passam gradualmente para classes altimétricas mais baixas e mais altas, quando se constata a presença de aluviões e rochas pré-cambrianas respectivamente. As vertentes exibem direções preferências para NE e SE, mas com número de vertentes é menor do que em as outras unidades geomorfológicas.

\section{PATAMARES DISSECADOS DO ESPINHAÇO}

Modelados de dissecação homogênea e diferencial caracterizados por formas de topos convexos, com baixa densidade de drenagem e ocorrência localizada de restos de planos desnudados.

Esses relevos foram elaborados em litologias do Supergrupo Espinhaço. Nesse compartimento a rede de drenagem expressa o forte controle estrutural, conduzindo a atuação dos processos erosivos.

A rede de drenagem nesses patamares torna-se encaixada com terrenos mais acidentados, além de feições e alinhamentos subordinados às estruturas geológicas, exibindo um padrão geral retangular com canais principais estabelecidos em lineamentos estruturais.

Esta unidade geomorfológica é delimitada por zonas de maior declividade, correspondentes a alinhamentos de elementos e unidades geomorfológicas que se manifestam, como escarpas proeminentes cristas e vales retilíneos e vertentes bem definidas de direções preferências para NW e SW.

Os topos aplainados das serras quartzíticas representam uma feição marcante nas bordas da Bacia Hidrográfica do Rio Congonhas, estando associadas à coberturas detrítico-lateríticas com limites retilíneos.

\section{PLANALTO DISSECADO DO ALTO JEQUITINHONHA}

Modelados de dissecação homogênea, caracterizados por feições de morros e morrotes com vertentes convexas e de inclinação moderada a alta sustentados por rochas do Grupo Macaúbas. A drenagem exibe padrão geral retangular com canais principais estabelecidos em lineamentos estruturais e densidades de drenagem baixa a média.

Com alto grau de dissecação, o relevo exibe alinhamentos em direções NE (principalmente N0-30), e NW (principalmente N300-360), coincidindo com os trends principais de fraturas, falhas e xistosidade, que condicionam os processos morfodinâmicos.

Esta unidade ocupa parte da bacia situada a leste, além das manchas situadas ao sul (cabeceira), aonde o relevo é forte ondulado a montanhoso. Nas declividades intermediárias (suave ondulado a forte ondulado), ocorre o fundo do vale na porção da alta cabeceira do Rio Congonhas e os médio-altos cursos de alguns de seus tributários da margem esquerda. As vertentes bem definidas exibem direções preferências para SE, NNW e NNE, com coberturas coluvionares.

A localidade do barramento situa-se neste planalto, em um vale aberto e formado por rochas quartzíticas que formam feições ruiniformes, à exceção da faixa miloníticas que se caracteriza por coberturas de solos e terrenos menos rugosos.

\section{PLANíCIE ALUVIAL}

Nesta porção ocorre a porção mais rebaixada da Bacia Hidrográfica do Rio Congonhas, com vale aberto formando encostas mais suaves de fundo achatado e baixas declividades. O Rio Congonhas adota um padrão meandrante em vale encaixado, e juntamente com os afluentes nesta unidade, assumem padrão subdendrítico, e maiores densidades de drenagem da bacia. 


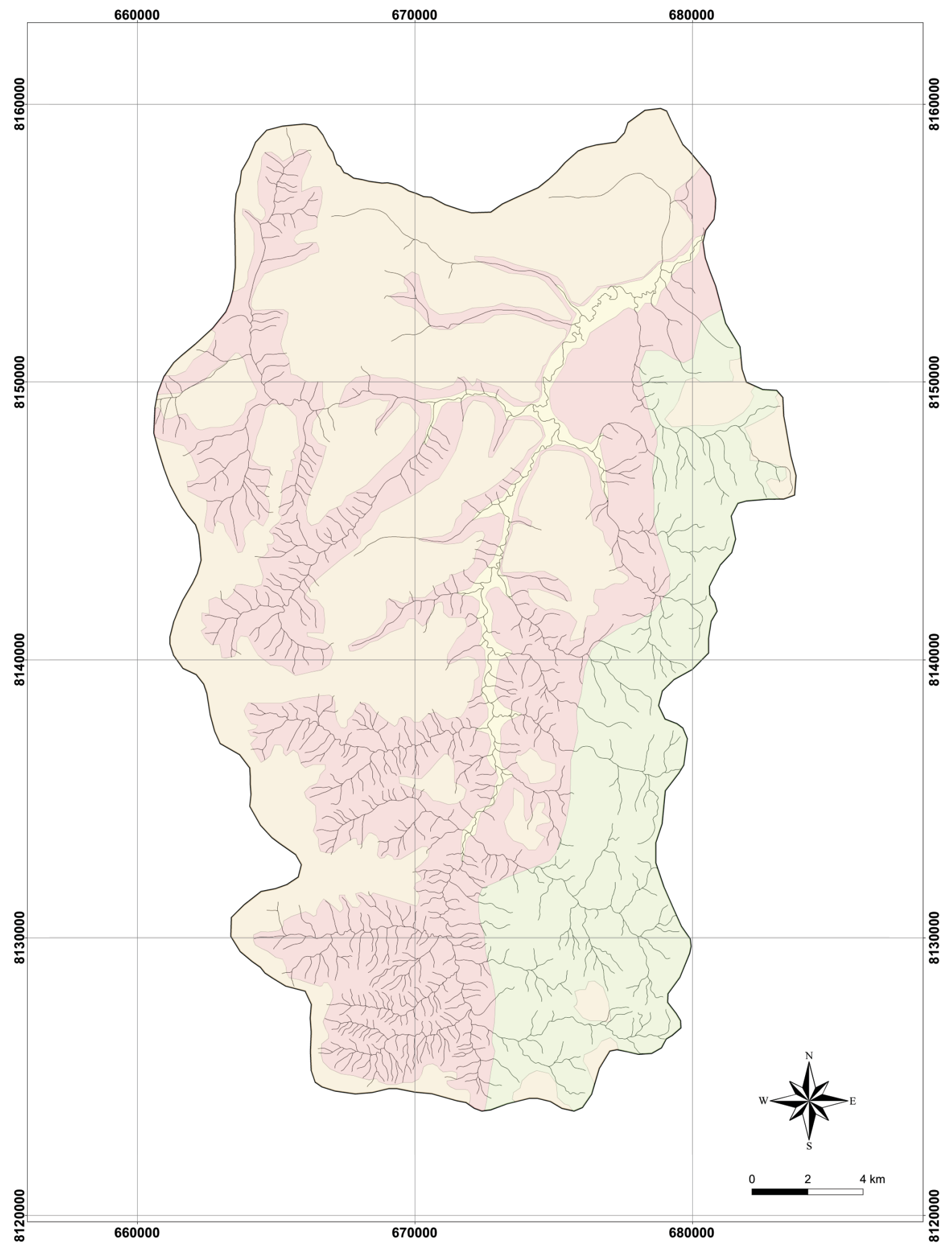

\section{Unidades geomorfológicas}

Chapadas do Alto Jequitinhonha

Patamares Dissecados do Espinhaço

Planalto Dissecado do Alto Jequitinhonha Planície Aluvial

Figura 6: Compartimentos geomorfológicos na Bacia Hidrográfica do Rio Congonhas. 


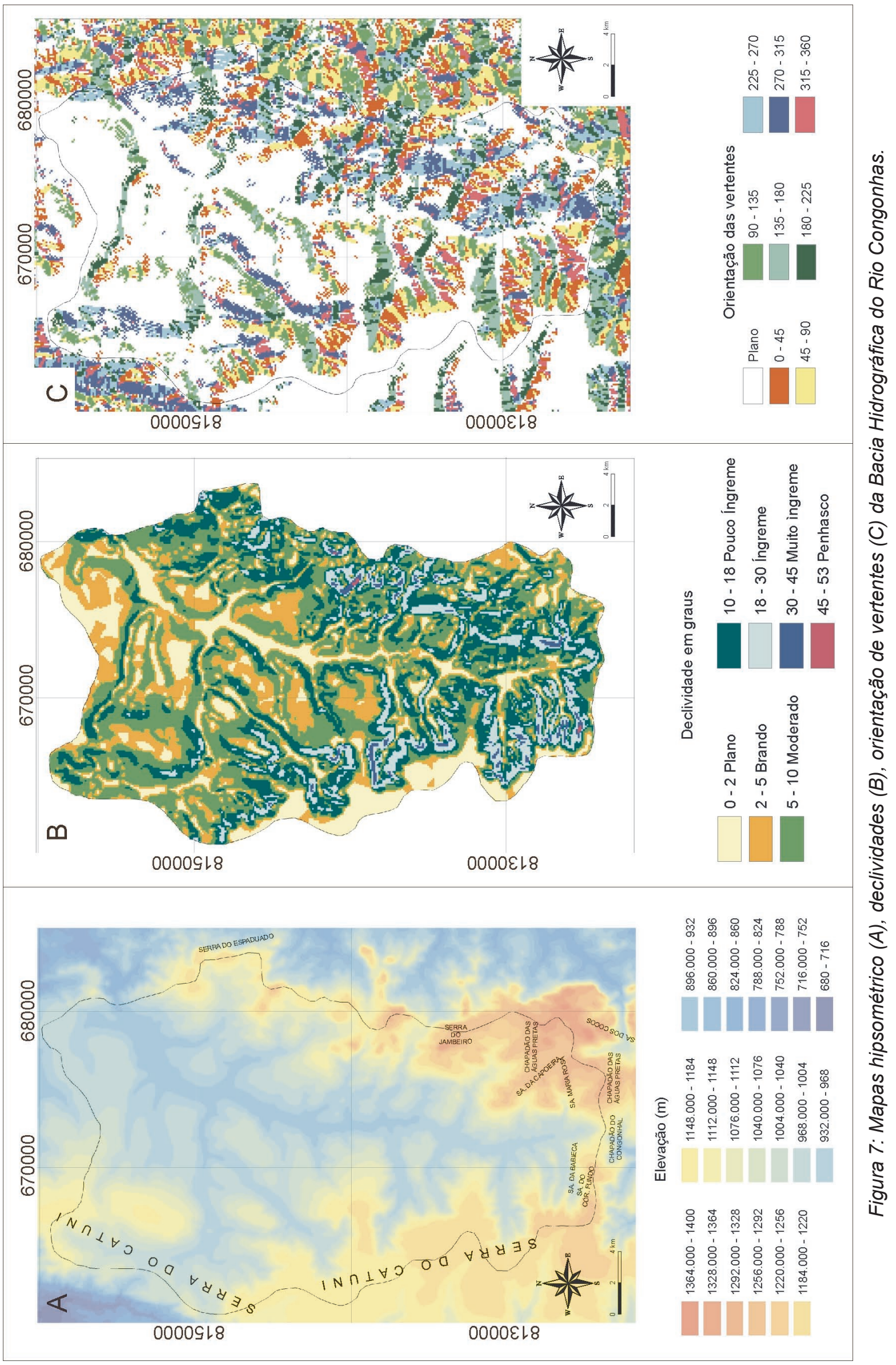


Nas cabeceiras o vale do Rio Congonhas é cercado por encostas íngremes, escarpadas e ravinadas, e adquire um traçado retilíneo encaixado em uma estrutura tectônica.

\section{DINÂMICA SUPERFICIAL}

\section{Fenômenos cársticos e potencial espeleológico}

Na Bacia Hidrográfica do Rio Congonhas ocorrem pequenos abrigos e condutos centimétricos em quartzitos, porém que não configuram cavernas. Estas feições são desenvolvidas na formação de um aqüífero fissural, que apresentam feições estruturais com maior ou menor incidência e densidade de fraturas responsáveis por variações locais na permeabilidade. Tais comportamentos devem-se ao alargamento da abertura de juntas, e ao melhor desenvolvimento das descontinuidades em rochas mais competentes. Nestas juntas ocasionalmente ocorre o processo de remoção mecânica de grãos (piping) promovendo a ampliação de algumas juntas formando pequenos condutos.

Analisando os dados do cadastro da SBE (Sociedade Brasileira de Espeleologia), confirmou-se que não há nenhuma incidência de caverna conhecida na área. Da mesma forma, moradores locais desconhecem a presença de cavernas na região de estudo.

\section{SUSCEPTIBILIDADE GEOTÉCNICA}

$\mathrm{Na}$ área de estudos não foram identificados pontos de degradação ambiental atuantes, indicando condições morfológicas de equilíbrio com o nível de base local. Dessa forma, algumas unidades geológicas em função da sua susceptibilidade geotécnica podem estar atuantes de forma esporádica sob o ponto de vista da dinâmica superficial.

As unidades pré-cambrianas (Grupo Macaúbas e Supergrupo Espinhaço) são favoráveis ao deslocamento de blocos e matacões devido às características físicas, além do processo de remoção mecânica de grãos (piping) promovendo a ampliação de algumas juntas. As coberturas detrito-lateríticas, coluviões e mantos de alteração podem ser mais susceptíveis a movimentos de massa, porque podem ser considerados solos colapsáveis. $\mathrm{Na}$ área de ocorrência dessa espessa cobertura cenozóica, porosa e permeável, a densidade da drenagem é mais baixa, porque predomina o processo de infiltração de águas pluviais. Esses solos têm baixa compacidade e são os que apresentam uma considerável e rápida redução de volume quando submetidos a um aumento brusco de umidade, sem variação da tensão total a que são submetidos.

\section{HIDROGEOLOGIA}

Pode-se estima-se preliminarmente uma reserva permanente de $3,42 \times 10^{3} \mathrm{~m}^{3}$ de água subterrânea na Bacia Hidrográfica do Rio Congonhas, com área de $577 \mathrm{~km}^{2}$, espessura saturada de 60 metros e porosidade eficaz 0,001 , devido ao desconhecimento da distribuição espacial dos coeficientes de armazenamento ou porosidade, e a conectividade em profundidade do sistema fissural.

A compartimentação dos sistemas aqüíferos foi realizada com base nos litotipos e descontinuidades presentes, e da interpretação da natureza da porosidade apresentada pelos mesmos. As unidades aqüíferas podem ser agrupadas em dois sistemas de aqüíferos distintos: sistema granular ou poroso e sistema fissural (Tabela 2 e Figura 8).

\section{Sistema granular ou poroso}

Composto pelos depósitos cenozóicos, formando Aqüifero Aluvial e Aqüifero Coberturas DetritoLateríticas e Mantos de Ateração, com nível d'água subterrânea profundo, devido à sua condição topográfica elevada, pequena espessura saturada e baixa vazão específica. Suas condições de ocorrência favorecem uma rápida drenagem e alimentação dos cursos d'água, tendo importante função reguladora do escoamento superficial.

Tabela 2: Unidades aqüiferas da área estudada e características hidráulicas. Condutividades hidráulicas estimadas com base nas características texturais e estruturais das rochas. Valores tabelados extraídos de Freeze \& Cherry (1979) e Fetter (1994).

\begin{tabular}{|c|c|c|c|}
\hline $\begin{array}{l}\text { Sistema de } \\
\text { Aqüíferos }\end{array}$ & Unidade aqüífera & Tipo de porosidade & $\begin{array}{l}\text { Condutividade } \\
\text { hidráulica }(\mathrm{cm} / \mathrm{s})\end{array}$ \\
\hline \multirow[b]{2}{*}{$\begin{array}{c}\text { Granular ou Po- } \\
\text { roso }\end{array}$} & Aluvial & $\begin{array}{l}\text { permeável, porosidade } \\
\text { primária: intergranular }\end{array}$ & $10^{-7}$ a $10^{2}$ \\
\hline & $\begin{array}{c}\text { Coberturas detrito- } \\
\text { lateríticas e mantos } \\
\text { de alteração }\end{array}$ & $\begin{array}{l}\text { permeável, porosidade } \\
\text { primária: intergranular }\end{array}$ & $10^{-7}$ a $10^{-1}$ \\
\hline Fissural & $\begin{array}{l}\text { Supergrupo Espin- } \\
\text { haço } \\
\text { Grupo Macaúbas }\end{array}$ & $\begin{array}{l}\text { impermeável, porosidade } \\
\text { secundária: } \\
\text { planos de estratificação, } \\
\text { descontinuidades } \\
\text { (fratura, falhas, xistosi- } \\
\text { dade) proto-condutos }\end{array}$ & $10^{-7}$ a $10^{-2}$ \\
\hline
\end{tabular}


Nos períodos sem chuva a água percola pelo sistema granular ou poroso de forma lenta e gradativa para o topo do aqüífero fissural, responsável pelo abastecimento do deflúvio da bacia. Já nos períodos chuvosos, a infiltração da água é alta e a profundidade do nível de água subterrâneo se eleva, enquanto a frente de molhamento estende-se em direção às camadas mais profundas ou de menos permeabilidade do sistema fissural. A direção do fluxo da água na camada saturada do sistema granular ou poroso é desviada ao longo da declividade do terreno, resultando no escoamento subsuperficial, que é o responsável pelo aumento do deflúvio da bacia.

\section{AQÜÍFERO ALUVIAL}

Apresentam pequenas espessuras (dezena de metros), contido nos aluviões que ocorrem na Bacia Hidrográfica do Rio Congonhas. Apresentam níveis d'água próximo à superfície e recebem recarga direta das águas de escoamento superficial, com as quais mantêm conexão hidráulica constituindo uma zona de trocas ativas rio-aqüífero, e por infiltração meteórica.

Os aqüíferos aluviais apresentam o nível de água próximo à superfície durante a estação chuvosa e algum tempo após o inicio da estação seca, sendo cursos de água efluentes. $\mathrm{Na}$ estação seca ocorre rebaixamento acentuado, com cursos de água influentes. Embora não se tenha informação local da condutividade hidráulica, a mesma deve variar bastante em função da natureza dos sedimentos como arredondamento, seleção e empacotamento.

\section{AQÜÍFERO COBERTURA DETRITO- LATERÍTICAS E MANTO DE ALTERAÇÃO}

Compreendem os pacotes de sedimentos detríticos e coberturas de natureza colúvio-eluvionar, ocupando uma área de cerca de $270 \mathrm{~km}^{2}$, perfazendo $47 \%$ da área de recarga, e assumem importância em contribuição direta no trecho do Rio Congonhas a partir do afluente Congonhas.

Constitui as principais áreas de recarga, que ocorre diretamente através da percolação de água meteórica em suas amplas e planas chapadas com baixa densidade de drenagem, que configuram condições favoráveis a infiltração. Nesta porção apresentam níveis d'água mais profundos, em comparação ao Aqüífero aluvial.

As coberturas têm em geral permeabilidade elevada, razão pela qual as águas neles infiltradas percolam até o topo do substrato impermeável de rochas do Supergrupo Espinhaço ou Grupo Macaúbas, formando um lençol freático pouco espesso. $\mathrm{O}$ escoamento dessas águas é comandado pela inclinação do substrato e pelos sistemas de fraturas subjacentes, formando zonas de descarga nas escarpas e nas bordas de chapadas, constituindo fontes ou nascentes de encostas no contato com as rochas do Supergrupo Espinhaço ou Grupo Macaúbas quando estão pouco alteradas, devido a diferença de porosidade e permeabilidade entre as unidades geológicas, para os principais rios da bacia.

Quando as rochas do Supergrupo Espinhaço ou Grupo Macaúbas apresentam espessuras razoáveis de material alterado ou com descontinuidade adequada (descontinuidades com extensão, abertura e grau de conectividade) é favorável à recarga para o meio fissurado. Neste caso o aqüífero atua como meio condutor, e não armazenador. Devido ao clima semi-árido regional, com elevada evapotranspiração potencial e baixa precipitação ocasionando déficit hídrico, provavelmente o manto de intemperismo não é saturado.

\section{SISTEMA FISSURAL}

O Aqüifero Fissural corresponde a maior parcela do fluxo de base dos rios da região, considerando a parcela de recarga indireta que recebem dos aqüíferos de cobertura. No sistema fissural ocorre o Aqüifero Supergrupo Espinhaço e Aqüifero Grupo Macaúbas, que apresentam feições estruturais com maior ou menor incidência e densidade de fraturas, responsáveis por variações locais na permeabilidade. A recarga deste aqüífero ocorre através da infiltração direta em suas descontinuidades através de água meteórica ou infiltração através da cobertura que forma o manto de intemperismo.

Nas zonas de colinas e serras predominam os aqüíferos em meio fissural, que apresentam pequeno manto de alteração, que aloja rede de drenagem mais densa com direções concordantes aos padrões estruturais regionais, facilitando o escoamento superficial em detrimento da infiltração. Como o sistema fissural têm uma permeabilidade primária muito baixa ou nula, a ocorrência e o armazenamento de água restringem-se aos sistemas de descontinuidades (juntas, fraturas, falhas, estratificação, xistosidade) e/ou raras cavidades provocadas por dissolução da rocha. Embora algumas fontes ou pequenas filtrações possam ocorrer nas encostas e cabeceiras de drenagem, a descarga desses aqüíferos se processa principalmente no fundo dos vales.

\section{VULNERABILIDADE DOS AQÜÍFEROS À CONTAMINAÇÃO}

Na simulação do risco de contaminação da água e do solo pelos efluentes gerados, os sistemas aqüíferos a vulnerabilidade do aqüífero à contaminação foi calculada em Média a Baixa, com exceção do Aqüífero Aluvial cujo nível d'água encontra-se com menor profundidade (Tabela 3).

\section{RECURSOS MINERAIS}

Na região de estudo não são encontrados depósitos minerais importantes e não existe atividade de explotação mineral, com insignificante atividade garimpeira de 


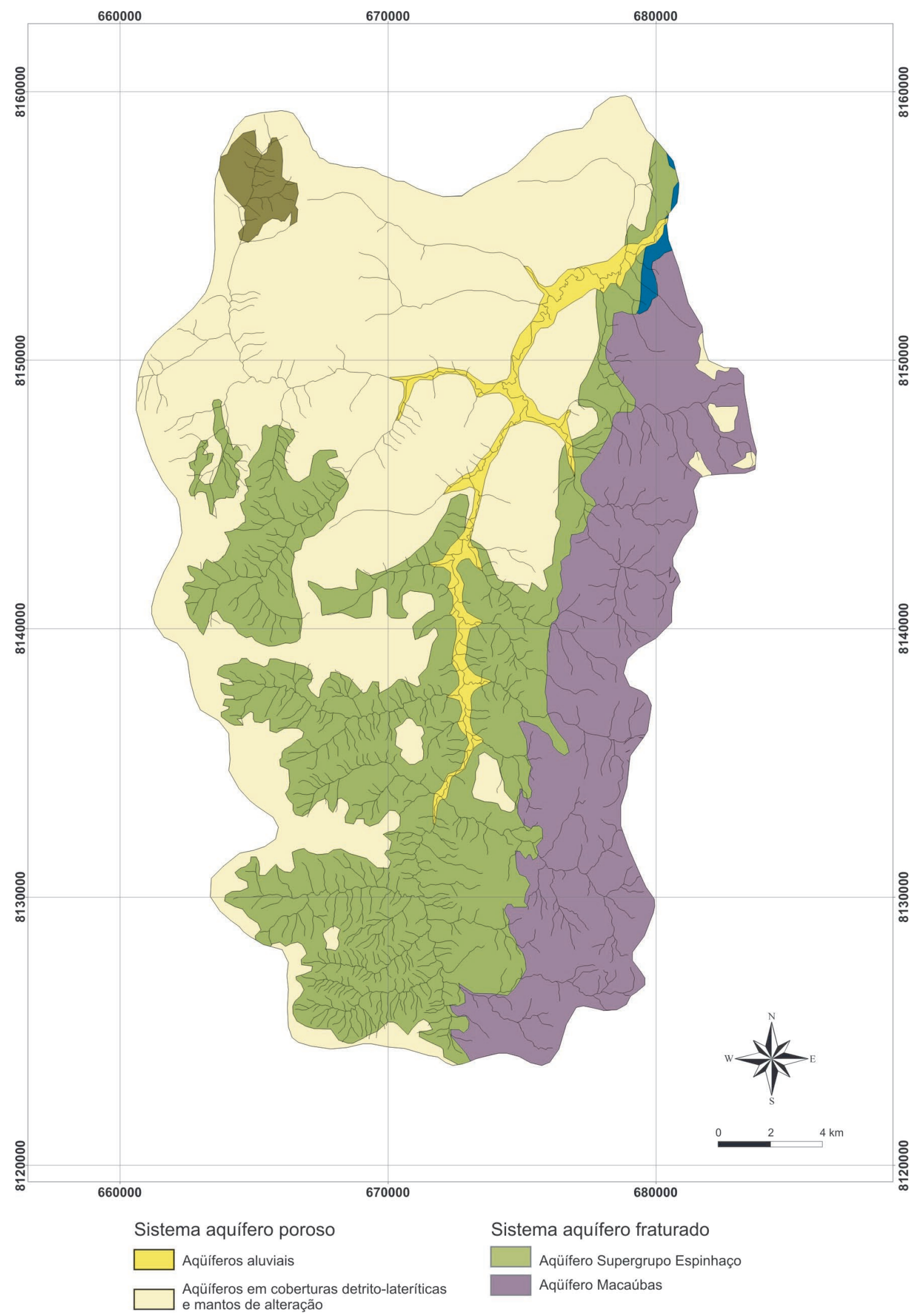

Figura 8: Unidades Aqüíferas da Bacia Hidrográfica do Rio Congonhas.

diamante nas cabeceiras do Rio Congonhas (Serra do Catuni). Outros bens minerais encontrados, que podem ser aproveitados eventualmente, são quartzo (de veio), depósitos de caolim e ainda os granitóides, como material de construção ou rocha ornamental.

Veios de quartzo são encontrados principalmente na região ocupada pelos quartzitos do Supergrupo Espinhaço. Embora os veios observados sejam pequenos e irregulares, toda esta região é potencialmente importante no que diz respeito a jazimentos desta natureza. Gnaisses, granitóides e veios pegmatóides ocorrem quase sempre intemperizados, dando como 
Tabela 3: Parâmetros GOD (Grau de confinamento hidráulico, Ocorrência de substrato suprajacente e

Distância do nível da água subterrânea) e graus de vulnerabilidade dos aqüíferos à contaminação calculados para os sistemas aqüiferos identificados.

\begin{tabular}{|c|c|c|c|c|c|}
\hline Sistema & $\mathbf{G}$ & 0 & $\mathbf{D}$ & Resultado & $\begin{array}{c}\text { Grau de Vulnera- } \\
\text { bilidade }\end{array}$ \\
\hline Aqüífero Aluvial & 1,0 & 0,7 & 0,9 & 0,63 & Alta \\
\hline $\begin{array}{c}\text { Aqüifero Cobertura detrito-lateríti- } \\
\text { ca } \\
\text { e Manto de alteração }\end{array}$ & 1,0 & 0,4 & 0,8 & 0,32 & Baixa/Média \\
\hline Aqüífero Supergrupo Espinhaço & 0,6 & 0,4 & 0,8 & 0,192 & Baixa \\
\hline Aqüifero Macaúbas & 0.6 & 0.4 & 0.8 & 0.192 & Baixa \\
\hline
\end{tabular}

produto final caolim proveniente da decomposição dos feldspatos. A maior parte dos depósitos é muito pequena e sem significado econômico.

\section{CONCLUSÃO}

Este estudo apresentou os estudos desenvolvidos para a composição do quadro atual do meio físico para o diagnóstico ambiental da Bacia Hidrográfica do Rio Congonhas. Não foram identificados pontos de degradação ambiental atuantes na bacia, indicando condições morfológicas de equilíbrio com o nível de base local. Com a implantação de projetos para o aumento da disponibilidade hídrica, como a Barragem Congonhas, poderão surgir novas áreas para agricultura irrigada, que contribuirão para o aumento dos processos erosivos, gerando um fluxo maior de sedimentos aos corpos d'água.

Uma das mais importantes modificações decorrentes do enchimento dos reservatórios se processa no subsolo, já que volumes significativos de água oriundos da represa percolam para o seu interior, realimentando os aqüíferos livres já existentes. Atualmente a recarga da água subterrânea nos aqüíferos da região é assegurada pela água de origem meteórica. Com a implantação da barragem, essa reposição será continua nos locais de saturação do nível de água, aumentando o valor de recarga nos aqüíferos fissurais e assegurando menor profundidade nos aqüíferos granulares ou porosos.

O equilíbrio dinâmico original entre o vale/ aqüífero é rompido com o enchimento do reservatório. Inicialmente, a superfície potenciométrica da água subterrânea sofre ajustes transitórios passando para mudanças permanentes a longo prazo.

Atualmente a recarga da água subterrânea nos aqüíferos da região é assegurada pela água de origem meteórica. Com a implantação da barragem, essa reposição será continua nos locais de saturação do nível de água, aumentando o valor de recarga nos aqüíferos fissurais e assegurando menor profundidade nos aqüíferos granulares ou porosos. O equilíbrio dinâmico original entre o vale/aqüífero é rompido com o enchimento do reservatório. Inicialmente, a superfície potenciométrica da água subterrânea sofre ajustes transitórios passando para mudanças permanentes a longo prazo.

Inicialmente o nível de água sofrerá um aumento transitório, aonde ocorrerá a infiltração de água, à partir do reservatório, para a zona não-saturada do Aqüifero Supergrupo Espinhaço, Aqüifero em Coberturas detrito-lateríticas e mantos de alteração e Aqüifero Grupo Macaúbas, ou seja, o reservatório passará a alimentar os aqüíferos em uma inversão de sentido do fluxo. O Aqüífero Aluvial será totalmente coberto pela lamina de água da barragem. Após esse período transitório, o nível d'água subterrâneo da bacia será elevado e os aqüíferos contribuirão novamente para o Rio Congonhas, com uma tendência geral de decréscimo de ação a partir da barragem em direção a montante e das bordas do reservatório em direção aos limites da bacia, além de diminuir a descarga de base do aqüífero para o reservatório.

Com a formação do reservatório a área superficial de recarga da bacia por água meteórica será reduzida e teremos uma menor área de infiltração e uma recarga menor por área para os seguintes aqüíferos: coberturas detrito-lateríticas e mantos de alteração e Grupo Macaúbas. Para o Aqüífero Supergrupo Espinhaço praticamente não ocorrerão mudanças, devido ao fato de que essas rochas ocorrem associadas as maiores altitudes da região que não serão inundadas com o enchimento do reservatório. Mas a taxa de infiltração será maior pela maior proximidade com o nível freático, sendo que ocorrerá uma redução de volume de zona não-saturada. Com a formação do reservatório, o escoamento superficial também será maior devido a maior inclinação das cabeceiras de drenagem, além da diminuição da profundidade do nível de água subterrânea local. Regiões que atualmente se encontram na zona não-saturada, como a maior porção do Aqüifero em Coberturas detrito-lateríticas e mantos de alteração serão atingidos com o nível de saturação mais alto.

Dessa forma, deverá ocorrer uma diminuição pontual na recarga para o aqüífero fissural, devido à diminuição de zona não-saturada, implicando em menor contribuição desta via pra as vazões da bacia, além do aumento de umidade subsuperficial das unidades aqüíferas de cobertura.

Em contrapartida, a infiltração deve ser maior nas coberturas detrito-lateríticas e mantos de alteração, 
devido às características composicionais, e a infiltração vertical para o Aqüífero Macaúbas será beneficiada pela infiltração direta na área do reservatório, causando um aumento nas vazões e balanceando deste modo a vazão total da bacia. Dessa forma, acredita-se que o impacto não será significativo para a recarga dos aqüíferos, já que no balanço de massa final ocorrerá um maior volume de água infiltrada para o sistema de aqüífero fissural.

Alterações no nível da água subterrânea no local podem causar instabilização de encostas marginais dos corpos d'água, favorecendo a desestabilização das margens, podendo provocar escorregamentos e desbarrancamentos. Podem ocorrer escorregamentos por percolação de água, principalmente nos materiais que compõem as coberturas detrito-lateríticas e mantos de alteração, favorecendo a erosão interna e aumentando movimentos de rastejo. É muito importante a impermeabilização por cobertura vegetal em áreas susceptíveis a erosão e desmoronamento.

Processos de erosão nos solos podem ser instalados, gerando o surgimento de feições erosivas (sulcos, ravinas ou boçorocas). Podem aparecer novas surgências perenes em encostas e vales que, a depender da vocação do solo e de outros condicionantes locais poderão se iniciar processos erosivos lineares.

As unidades pré-cambrianas (Grupo Macaúbas e Supergrupo Espinhaço) devido às características físicas são favoráveis ao deslocamento de blocos e matacões, além do processo de remoção mecânica de grãos (piping) promovendo a ampliação de algumas juntas. As coberturas detrito-lateríticas, coluviões e mantos de alteração podem ser mais susceptíveis a movimentos de massa, porque podem ser considerados solos colapsáveis. Na área de ocorrência dessa espessa cobertura cenozóica, porosa e permeável, a densidade da drenagem é mais baixa, porque predomina o processo de infiltração de águas pluviais. Esses solos têm baixa compacidade e são os que apresentam uma considerável e rápida redução de volume quando submetidos a um aumento brusco de umidade, sem variação da tensão total a que são submetidos.

Nas sub-bacias do Rio Congonhas, os córregos possuem cursos intermitentes em sua maioria. Se ocorrer modificações do regime fluvial das drenagens receptoras, podem ocorrer modificações no período de tempo em que ficam secos, aumentando as vazões médias à jusante e uma diminuição no pico de cheias.

$\mathrm{O}$ uso inadequado dos recursos naturais, como desmatamento, pastoreio, caça predatória, salinização, queimadas e o uso intensivo sem manejo adequado, pode iniciar ou acelerar os processos de desertificação, ocasionando no solo a perda da capacidade de retenção de água e de nutrientes, indispensável ao desenvolvimento da vegetação, além do assoreamento de mananciais.
Modificações no nível d'água subterrânea, como por exemplo, profundidades mais rasas, podem propiciar o aumento da evapotranspiração e, por conseguinte, o aumento do conteúdo salino nos solos sub-superficiais. Pode ocorrer afogamento de fossas sépticas localizadas na zona não-saturada, constituindo focos de contaminação nos aqüíferos.

Como prevenção para problemas ambientais, propõe-se ações de educação ambiental voltadas a conscientização da população que vive na Bacia Hidrográfica do Rio Congonhas. A população local pode ser atuante na identificação e prevenção de fatores degradantes que proporcionam impactos ambientais, principalmente na conservação dos canais fluviais, abrangendo preservação das áreas de cabeceiras de drenagem de forma a evitar o surgimento de pontos de erosão, uso correto do solo, preservação dos corpos d'água e desenvolvimento sustentável.

\section{AGRADECIMENTOS}

Agradecemos à EQUIPE UMAH - Urbanismo, Meio Ambiente e Habitação, responsável pela Elaboração dos Estudos de Impacto Ambiental (EIA) e do Relatório de Impacto Ambiental (RIMA) da Barragem Congonhas.

\section{REFERÊNCIAS}

CETEC. 1980. Estudo Integrado dos Recursos Naturais dos Rios Jequitinhonha e Pardo. Hidrogeologia, Belo Horizonte.

ESCHWEGE, W. L. von 1822. Geognostisches Gemälde von Brasilien und wahrscheinliches. Muttergestein der Diamanten. Weimar (Landes Industrie Comptoir), 44 p.

FETTER, C.W. 1994. Applied hydrogeology. McMillan College Publ. Co. New York, 680p.

FOSTER, S.; HIRATA, R.; GOMES, D.; D'ELIA, M.; PARIS, M. 2002. Protección de la Calidad del Agua Subterránea. Groundwater Management Advisory Team (GW-MATE), Banco Mundial, Washington, D.C.

FREEZE, R.A. \& CHERRY, J.A. 1979. Groundwater. Englewood Cliffs: Prentice-Hall, 604p.

GROSSI SAD, J. H., LOBATO, L. M.; PEDROSA-SOARES, A.C.; SOARES-FILHO, B.S. 2002. Projeto Espinhaço.CD-ROM (texto e anexos). COMIG, Belo Horizonte, $2^{\mathrm{a}}$ ed., 2693 p.

IBGE. 1997. Diagnóstico Ambiental da Bacia do Rio Jequitinhonha - Diretrizes Gerais para a Ordenação Territorial. Fundação Instituto Brasileiro de Geografia e Estatística - IBGE, Diretoria De Geociências, 1a Divisão De Geociências Do Nordeste DIGEO 1/Ne .1, 64 p.

IGA - Projeto Radar Minas Gerais. 1978. Mapa Geológico da Folha Montes Claros 1/500.000. Secretaria de Estado, Ciência e Tecnologia, Instituto de Geociências Aplicadas, BeloHorizonte

KING L. C. 1956. Geomorfologia do Brasil Oriental. Rev. Bras. Geog., 18(2): 147-266.

SAADI A. 1995. A geomorfologia da Serra do Espinhaço em Minas Gerais e de suas margens. Geonomos, 3(1): 41-63.

SRTM. 2006. Shuttle Radar Topographic Mission. Disponível em $<$ http://seamless.usgs.gov>. Acesso: janeiro de 2006.

VAN EVERDINGEN, D. \& VAN GOOL, J. 1990. Quickplot; ploting program for orientation data. Newfoundland, Department of Earth Sciences, Memorial University of Newfoundland. 